\title{
A Relação Exemplar entre Autor e Revisor (e Outros Trabalhadores Textuais Semelhantes) E O Mito de Babel: Alguns Comentários sobre História do Cerco de lisboa, de José Saramago*
}

(The Exemplary Relationship between Author and Proofreader (as Well as Other Similar Textual Workers) and the Myth of Babel: A Few Comments on the History of the Siege of Lisbon, by José Saramago)

$$
\begin{array}{r}
\text { Rosemary ARROJO } \\
\text { (Professor of Comparative Literature } \\
\text { Director of Center of Research in Translation - Binghamton University } \\
\text { e Professora Titular Emérito - Unicamp) }
\end{array}
$$

ABSTRACT: This paper is part of a series of texts I have devoted to the exam of the treatment given to translators (as well as to other textual "workers" such as interpreters, proofreaders, critics and professional readers) in a few works of fiction. In this paper in particular I am interested in examining the relationship which is established between the narrator (as the Author's spokesman) and the "subversive" proofreader named Raimundo Silva in José Saramago's novel História do Cerco de Lisboa (History of the Siege of Lisbon). Just as in most theoretical approaches and in the way common sense generally treats this kind of textual work, Saramago's novel suggests that, from the point of view of the Author, who is the only one granted the right to be creative and both personally and professionally fulfilled, what needs to be protected is the "sacredness" of the original and everything it stands for.

KEY-WoRDs: Translation Studies; Translator's Invisibility; Authorship; Myth of Babel; José Saramago; History of the Siege of Lisbon.

* Uma versão preliminar deste trabalho, "O Mito de Babel como Cena Inaugural dos Estudos da Tradução”, foi apresentada como conferência durante o II CIATI - II Congresso Ibero-Americano de Tradução e Interpretação (“2001: Uma Odisséia na Tradução”), Faculdade Ibero-Americana, São Paulo, S. P., em 17 de maio de 2001. Outra versão preliminar, intitulada "The Myth of Babel and José Saramago's História do Cerco de Lisboa", foi apresentada como conferência plenária durante as "Jornadas de Teoría y Enseñanza de Traducción", promovidas pela Faculdade de Tradução e Interpretação da Universidade de Las Palmas de Gran Canaria, Las Palmas, Espanha, em 28 de novembro de 2001.

D.E.L.T.A., 19:EsPECIAL, 2003 (193-207) 
REsumo: Este trabalho faz parte de uma série de textos que tenho dedicado ao exame do tratamento dispensado ao tradutor (e a outros "trabalhadores" textuais semelhantes como intérpretes, revisores, críticos e leitores profissionais) em alguns textos de ficção. Especificamente neste ensaio, examino as relaçoes que se estabelecem entre o narrador (como porta-voz do Autor) e o revisor "subversivo" Raimundo Silva no romance de José Saramago, História do Cerco de Lisboa. Como na maioria das abordagens teóricas e como na opinião que o senso comum tipicamente reserva a esse tipo de trabalho textual, o livro de Saramago sugere que, a partir da perspectiva autoral, o que se deve proteger é a alegada "sacralidade" do original, como propriedade privada do Autor, e somente a este se reserva o direito à criatividade e a uma vida (pessoal e profissional) plena.

Palavras-Chave: Estudos da Tradução; Invisibilidade do Tradutor; Mito de Babel; José Saramago; História do Cerco de Lisboa.

E o Senhor disse: "Eles constituem apenas um povo e falam uma única língua. Se principiarem desta maneira, coisa nenhuma os impedirá, de futuro, de realizarem todos os seus projectos. Vamos, pois, descer e confundir de tal modo a linguagem deles que não se compreendam uns aos outros." E o Senhor dispersou-os dali para toda a face da terra, e suspenderam a construção da cidade. Por isso, lhe foi dado o nome de Babel, visto ter sido lá que o Senhor confundiu a linguagem de todos os habitantes da terra.

Génesis, 11, 1-9, A Bíblia Sagrada (Lisboa, Difusora Bíblica, 1988)

A situação profissional do tradutor, geralmente associada a uma reputação de traidor marginal e de escritor desajeitado, e as relações entre essa situação e as concepções teóricas dominantes acerca da tradução têm sido um tema constante de minha reflexão (cf., por exemplo, Arrojo 1998a). Tenho tentado apontar, por exemplo, como essas relações são uma conseqüência direta de concepções de "original" e de autoria que partem de noções essencialistas de linguagem, segundo as quais seria possível congelar significados e protegê-los em "invólucros" textuais que deveriam ser abordados com todo o cuidado por tradutores e leitores determinados apenas a resgatar e a reproduzir os significados originalmente definidos pelo autor, sem qualquer pretensão de interferir no texto a ser traduzido. 
Além de rever algumas das principais tendências teóricas dos estudos da tradução e de me deter no tratamento que essas tendências têm reservado ao tradutor e à sua atividade (cf., por exemplo, Arrojo 2000a e Arrojo 2000b), tenho me dedicado também ao exame de alguns textos de ficção que tematizam a tradução, ou algum outro trabalho textual semelhante, em busca das relações que estabelecem entre autoria e interpretação, e entre o chamado "original" e sua reprodução, na forma de uma leitura ou tradução. Em trabalhos recentes, tenho abordado o trajeto de alguns personagens de ficção associados, direta ou indiretamente, às atividades de escritura, interpretação ou tradução e que habitam a obra de autores como Borges, Kafka, Poe e o húngaro Dezsö Kosztolányi (Arrojo 1998, 2000, 2002, 2002a). O pressuposto geral que tem nutrido esse exame é de que o tratamento conferido aos personagens em questão, como o senso comum e como a grande maioria das abordagens teóricas, reflete concepções dominantes sobre a atividade tanto daqueles que se dedicam à produção de "originais" como dos trabalhadores textuais menos prestigiados - tradutores e intérpretes, ou críticos e leitores profissionais - geralmente colocados à margem de qualquer possibilidade de criatividade e de reconhecimento público.

Minha reflexão acerca das complexas relações que parecem se estabelecer entre o Autor (e as figuras autorais que cria e que - implícita ou explicitamente - o representam) e seus personagens dedicados à leitura ou à tradução tem se baseado, sobretudo, num texto fundamental de Freud (1983) sobre a escritura e os escritores de ficção, em que o fundador da psicanálise defende a existência de uma relação íntima entre a construção de enredos e o desejo de dominar o real e moldá-lo como se fosse um texto que deve obedecer aos caprichos de seu criador e soberano. Ao comparar os escritores de ficção a "sonhadores em plena luz do dia" e, portanto, ao equiparar suas ficções a sonhos sobre os quais os escritores imaginam ter controle absoluto, Freud conclui que o que se busca na escritura de textos de ficção é uma sensação de "invulnerabilidade" que revela "Sua Majestade o Ego, o herói de todos sonho e de toda história" (ibidem, 15-26) ${ }^{1}$. Além desse ensaio de Freud, têm sido importantes para o projeto em questão algumas relações estabelecidas por Nietzsche entre as noções de criação, construção e poder e, em especial, a noção do "desejo de potência", descri-

\footnotetext{
1 Esta e todas as outras traduções de trechos citados a partir de edições em inglês são minhas.
} 
to como "o impulso criador e procriador da vida", compatível com sua visão da linguagem como sendo fundamentalmente retórica e, conseqüentemente, incapaz de revelar supostas essências ou significados intrínsecos" (cf. Schrift 1990: 191).

A partir dessa perspectiva que se propõe associar Freud a Nietzsche, creio ser possível compreender de uma forma mais abrangente, por exemplo, a noção tão amplamente difundida segundo a qual a tradução e aqueles que a ela se dedicam devem se manter absolutamente invisíveis e subservientes à obra e às intenções do Autor, como se essa fosse uma opção possível ou atingível. Afinal, no texto criado pelo Autor, que emergeria de seu desejo de ser invulnerável ao desejo autoral do outro, ou, como poderíamos argumentar a partir de Nietzsche, de seu "desejo de potência", não deve haver lugar para a "criatividade" do leitor, ou qualquer versão da "visibilidade" do tradutor, vistos como forasteiros que, sobretudo conscientemente, poderiam acabar usando o texto alheio como tela para a projeção de seu próprio desejo de potência. ${ }^{2} \mathrm{O}$ conto húngaro, "O Tradutor Cleptomaníaco” (Kosztolányi 1996), por exemplo, fornece uma ilustração bem-humorada da noção de texto enquanto propriedade privada do Autor, tão arraigada às concepções textuais tradicionais e, particularmente, às concepções dominantes de tradução (cf. Arrojo 1998 e 2002). Como nos comunica o narrador de Kosztolányi, o original, mesmo quando for inadequado ou digno de desprezo, representa "a quase indiscutível sacralidade da propriedade privada" (10). Nesse contexto, a interferência do tradutor, por mais bem intencionada e apropriada que seja, será sempre o ato de um intruso mal visto, condenado à missão impossível de repetir os significados de outro sem tocá-los e sem marcá-los com seu próprio desejo autoral. Assim, defende-se a produção dos "originais" como atividade essencialmente criativa e, uma vez criado, qualquer texto deverá ser (e significar) apenas aquilo que seu Autor, seu amo e senhor, desejar. Coerentemente, define-se a meta da tradução e/ou da interpretação com base numa ética que prega a proteção cega e incondicional do desejo e dos significados do Autor, sem que se questione, por exemplo, se esse tipo de proteção seria viável, ou não.

2 Embora não seja minha meta, neste trabalho, examinar o desejo do revisor e/ou do tradutor, nem a relação que estabelece com os textos e os autores que lê, ou traduz, remeto os leitores interessados a alguns trabalhos especificamente dedicados à questão: Arrojo 1993 e Frota 2000. 
Nessa linha de reflexão, o objeto do presente ensaio será o romance História do Cerco de Lisboa, de José Saramago (1998), originalmente publicado em 1989, cujo enredo gira em torno de um revisor de textos que, como o tradutor e o intérprete, é um trabalhador textual de quem se espera total fidelidade e respeito ao Autor. Como em geral se pensa o tradutor, Raimundo Silva, o personagem revisor de Saramago, é, a princípio, um escritor reprimido que não consegue se dedicar ao que realmente lhe apetece. Como tantos outros personagens semelhantes, é um homem solitário e tímido, "vivendo fechado em casa, triste como um cão sem dono" (299), que ganha (mal) a vida revisando textos que muitas vezes despreza, ${ }^{3}$ sempre respeitando, entretanto, a posição que lhe cabe na hierarquia do trabalho com as palavras:

Considere, senhor doutor, a vida quotidiana dos revisores, pense na tragédia de terem de ler uma vez, duas, três, ou quatro, ou cinco vezes, livros que, Provavelmente, nem uma só vez o mereceriam. Fique registrado que não fui eu quem proferiu tão gravosas palavras, conheço muito bem o meu lugar na sociedade das letras, voluptuoso, sim, confesso-o, mas respeitador. $(13)^{4}$

Um dia, entretanto, ao revisar um livro histórico sobre a retomada de Lisboa no ano de 1147 - intitulado História do Cerco de Lisboa - resolve ignorar essa hierarquia, além de todas as normas que regem seu monótono ofício, e acrescenta um "não" à linha que "redondamente afirma que os cruzados auxiliarão os portugueses a tomar Lisboa" (48). A partir desse ato de consciente e extrema interferência, em que assume, finalmente, seu desejo de rescrever o texto que revisa, sua vida muda. Imediatamente, deixa de pintar os cabelos brancos, ousando, portanto, tornar-se mais "visível" e mostrar sua "real" natureza, e apaixona-se pela Doutora Maria

\footnotetext{
3 De acordo com Edmund White, é possível encontrar semelhanças entre o revisor de Saramago e o grande poeta português Fernando Pessoa, que ganhava a vida como tradutor de documentos comerciais em Lisboa, ao mesmo tempo em que, "escondidamente", escrevia seus poemas e textos em prosa em diversos estilos e sob diversos heterônimos (1997). Como sugere o autor, poderíamos ainda associar o perfil do personagem Raimundo Silva às conhecidas biografias de Franz Kafka e Constantine Cavafy, e também ao "Pierre Menard, autor del Quijote", de Borges. Da mesma forma que Menard tenta reinventar a obra máxima de Cervantes, Raimundo tenta reescrever o mito fundador da história de Portugal (idem). A própósito do "Pierre Menard," de Borges, ver, por exemplo, Arrojo 1986: 13-22 e Arrojo1993a.

4 Como somos informados pela Companhia das Letras, responsável pela edição do livro no Brasil, "por desejo do autor, foi mantida a ortografia vigente em Portugal".
} 
Sara que, após a descoberta do seu ato subversivo, é contratada como coordenadora dos trabalhos de revisão da editora. Ao mesmo tempo, incentivado por ela, começa a escrever seu próprio livro, um romance que intitula História do Cerco de Lisboa, exatamente como o texto histórico que acabara de revisar e subverter.

Em primeiro lugar, merece destaque o poder praticamente absoluto que se atribui à figura do Autor no universo do personagem de Saramago, em que a partir da escritura é possível se criar e estabelecer o que é verdade. Para "o revisor que conhece o seu lugar, o autor, como tal, é infalível" (50). Porém, para Raimundo Silva, se o revisor tivesse o poder e o direito de escrever como o Autor, poderia mudar a realidade:

\footnotetext{
Os revisores, se pudessem, se não estivessem atados de pés e mãos por um conjunto de proibições mais impositivo que o código penal, saberiam mudar a face do mundo, implantar o reino da felicidade universal, dando de beber a quem tem sede, de comer a quem tem fome, paz aos que vivem agitados, alegria aos tristes, companhia aos solitários, esperança a quem a tinha perdida, para não falar da fácil liquidação das misérias e dos crimes, porque tudo eles fariam pela simples mudança das palavras, e se alguém tem dúvidas sobre estas novas demiurgias não tem mais que lembrar-se de que assim mesmo foi o mundo feito e feito o homem, com as palavras, umas não outras, para que assim ficasse e não doutra maneira. Faça-se, disse Deus, e imediatamente apareceu feito. (50)
}

Em relação "aos senhores autores", potencialmente capazes de façanhas divinas, que "vivem nas alturas $[\mathrm{e}]$ não gastam o precioso saber em despiciências e insignificâncias, letras feridas, trocadas, invertidas" (11), o modesto revisor somente pode nutrir um respeito incondicional e ocupar o outro lado dessa oposição clara que o enredo propõe entre escritura e leitura (ou revisão). Previsivelmente, o revisor, que não escolhe seu trabalho por vocação ("revisor de vocação é fenómeno desconhecido" [12]), além de "sóbrio" (15), deve tomar todo o cuidado para não melindrar os poderosos autores dos textos que corrige. Como somos informados, "o primeiro mandamento do decálogo do revisor que aspire à santidade" é que "aos autores deve-se evitar sempre o peso de vexações" (36). Contudo, mesmo antes de consumar seu ato subversivo, e embora "aspire à santidade", Raimundo, secretamente, não consegue reprimir seu desejo autoral e, enquanto lê e trata de emendar o trabalho alheio, não pode deixar de imaginar o texto que escreveria se pudesse estar no lugar privilegiado do Autor: 
[...] tudo aquilo não foi mais que pensamentos vagos da cabeça do revisor enquanto ia lendo e emendando o que escondidamente passara em falso nas primeiras e segundas provas. O revisor tem esse notável talento de desdobrar-se, desenha um deleatur ou introduz uma vírgula indiscutível, e ao mesmo tempo, aceite-se o neologismo, heteronimiza-se, é capaz de seguir o caminho sugerido por uma imagem, uma comparação, uma metáfora, não raro o simples som duma palavra repetida em voz baixa o leva, por associação, a organizar polifónicos edifícios verbais que tornam o seu pequeno escritório num espaço multiplicado por si mesmo, ainda que seja muito difícil explicar, em vulgar, o que tal coisa quer dizer. (22)

Como sabemos, o destino de Raimundo Silva toma um novo rumo quando suas "voluptuosidades" finalmente começam a emergir. "Pela primeira vez em tantos anos de ofício minucioso", o revisor começa a deixar de lado sua respeitosa dedicação ao texto que revisa pois não mais "lhe apetece o martírio", tendo-se tomado "de resoluta antipatia pela obra e pelo autor dela" (43). Fixa-se, então, numa linha das "quatrocentas e trinta e sete páginas fortíssimas de notas" (43), que se encontram sob sua responsabilidade profissional de revisor:

Está como fascinado, lê, relê, torna a ler a mesma linha, esta que de cada vez redondamente afirma que os cruzados auxiliarão os portugueses a tomar Lisboa. [...] A tensão chegou a pontos que Raimundo Silva, de repente, não pôde aguentar mais, levantou-se, empurrando a cadeira para trás, e agora caminha agitado de um lado para o outro no reduzido espaço que as estantes, o sofá e a secretária lhe deixam livre, diz e repete, Que disparate, que disparate [...] É um disparate, insiste Raimundo Silva como se estivesse a responder-nos, não farei semelhante coisa, e por que a faria, um revisor é uma pessoa séria no seu trabalho, não joga, não é prestidigitador, respeita o que está estabelecido em gramáticas e prontuários, guia-se pelas regras e não as modifica, obedece a um código deontológico não escrito mas imperioso, é um conservador obrigado pelas conveniências a esconder as suas voluptuosidades, dúvidas, se alguma vez as tem, guarda-as para si, muito menos porá um não onde o autor escreveu sim, este revisor não o fará. (48-49)

Coerentemente com a associação da figura autoral à de um deus onipotente, a luta entre o desejo do revisor de (indevidamente) assumir o lugar do Autor e mudar o curso da história e a ética que o prende à sua modesta profissão é apresentada como um embate absolutamente consciente "entre o campeão angélico e o campeão demoníaco, esses dois de que estão compostas e em que se dividem as criaturas, referimo-nos às humanas, sem exclusão dos revisores" (49). Como se sabe, esta "batalha, desgraçadamente, vai ganhá-la Mr. Hyde": 
percebe-se pela maneira como Raimundo Silva está a sorrir neste momento, com uma expressão que não esperaríamos dele, de pura malignidade, desapareceram-lhe do rosto todos os traços do Dr. Jekill, é evidente que acabou de tomar uma decisão, e que má ela foi, com a mão firme segura a esferográfica e acrescenta uma palavra à página, uma palavra que o historiador não escreveu, que em nome da verdade histórica não poderia ter escrito nunca, a palavra Não, agora o que o livro passou a dizer é que os cruzados Não auxiliarão os portugueses a conquistar Lisboa, assim está escrito e portanto passou a ser verdade [...] (49-50)

Além de idealizar o poder autoral de criar e estabelecer o que é verdadeiro, o enredo de Saramago sugere ainda que a felicidade pessoal, e até mesmo a possibilidade do encontro amoroso, são reservados apenas àquele que ousa deixar as sombras e ocupar o lugar privilegiado do Autor. Afinal, apenas depois de ousar rescrever o texto que revisa, e apesar de temer as conseqüências de seu ato, Raimundo passa a sentir "uma livre, uma desafogada sensação de prazer" (60). Simultaneamente, "chega mesmo a surpreender-se por nunca antes lhe ter ocorrido a idéia de alterar o sentido doutros livros que reviu. Num momento que lhe parece ser como se estivesse a desdobrar-se, a afastar-se de si mesmo, observa-se a pensar, e assusta-se um pouco" (50). A posição autoral, que o revisor passa a ocupar às custas de um ato de coragem que envolve a invasão do texto alheio, e que se associa diretamente a um ato de masculinidade, ou de virilidade plena, implica também a possibilidade de expressão de sua sexualidade e a capacidade de atrair uma mulher não apenas compatível mas, em vários aspectos, "superior", sobretudo a partir do ponto de vista do personagem: mais jovem, mais qualificada, mais atraente, mais bem sucedida. Enquanto revisor de textos subserviente às supostas intenções do autor do texto que revisa, Raimundo é praticamente assexuado, o que pode sugerir que a invisibilidade do leitor/revisor e sua "fidelidade" compenetrada ao Autor é quase uma forma de castração. Conseqüentemente, podemos concluir, somente poderá ser fiel e modesto o revisor que conseguir reprimir seu desejo autoral/sexual. O prazer do texto, ou o prazer de criar significados, diretamente associado ao prazer sexual, é algo que se reserva ao Autor, como figura masculina por excelência, e àqueles que são suficientemente corajosos (ou viris) para tomar e ocupar esse lugar privilegiado. 5 Aliás, como esclarece a narrativa, o interesse amoroso de Maria Sara pelo revisor

5 Para uma outra reflexão acerca de algumas relações entre o prazer textual, o prazer sexual e as atividades de escritura, leitura e tradução, cf. Arrojo 1995, em que me dedico ao exame do romance Se una notte d'inverno un viaggiatore, de Italo Calvino. 
depende, inclusive, de que ele efetivamente esteja cumprindo sua missão autoral: "Só uma pergunta mais, Diga, Já começou a escrever a História do Cerco de Lisboa, Já, Não sei se continuaria a gostar de si se me respondesse que não [...." (239).

Essa sugestão da posição autoral como um atributo "masculino" por excelência poderia também ser examinada à luz do ensaio fundamental de Lori Chamberlain sobre as relações entre as metáforas tipicamente associadas à escritura de "originais" e à tradução e os diferentes papéis sexuais tradicionalmente representados por homens e mulheres (1992). Segundo a autora,

A sexualização da tradução aparece talvez de forma mais familiar na conhecida expressão "les belles infidèles" - como as mulheres, sugere o aforismo, as traduções deveriam ser belas ou infiéis. A máxima se torna possível tanto pela rima em francês como pelo fato de que a palavra 'traduction' é feminina, tornando "les beaux infidèles" impossível. Essa máxima deve sua longevidade - surgiu no século XVII - não apenas à semelhança fonética: o que lhe confere sua aparência de verdade é o fato de que captura uma cumplicidade cultural entre as questões de fidelidade em tradução e no casamento. Para "les belles infidèles", a fidelidade se define por um contrato implícito entre a tradução (como mulher) e o original (como marido, pai, ou autor). (58)

Como tem argumentado a pesquisa de base feminista, associada a diversas disciplinas, "a oposição entre o trabalho de caráter produtivo e o de caráter reprodutivo organiza as formas pelas quais a cultura valoriza o trabalho: esse paradigma concebe a originalidade, ou a criatividade, em termos de paternidade e autoridade, relegando a figura da mulher a uma variedade de papéis secundários" (57). Chamberlain está particularmente interessada em examinar como essa oposição entre a produção e a reprodução tem definido as distinções tradicionalmente aceitas entre escritura e tradução. Enquanto se associa a primeira à originalidade, ao primordial e ao masculino, a segunda se relaciona ao que é derivado, secundário e feminino (idem).

Traçando um paralelo entre a reflexão de Chamberlain e minha leitura das relações entre autoria e revisão no texto de Saramago, podemos concluir que esse texto implicitamente sugere que, para que se mantenha o contrato implícito de "fidelidade" entre o revisor (e/ou o tradutor, o leitor, ou o intérprete) e o original e seu autor, ou seja, para que se possa proteger o máximo possível o original das investidas potencialmente "subversivas" do revisor, é necessário que este cumpra um destino semelhante ao papel 
tradicionalmente reservado às mulheres, colocadas à sombra e isoladas da ambição de ocupar o espaço de autoridade limitado aos homens, ou, talvez um destino comparável ao dos eunucos, os únicos homens autorizados a circular entre as mulheres do sultão, sem que lhe ameacem a "propriedade" e os direitos. Considerando-se sua trajetória, Raimundo Silva sabe, mais do que ninguém, que, enquanto espaço privilegiado do Autor, o original deve ser mantido, o máximo possível, longe do desejo autoral/sexual de revisores mal-intencionados. Mesmo quando o romance que pretende escrever ainda "não é um livro, [e] são apenas umas poucas dezenas de páginas com episódios soltos" (301), Raimundo impõe como "condiçãa" para sua eventual publicação que seja ele mesmo o revisor da obra: "Para quê, se o autor é sempre um mau revisor de si mesmo, Para que não venha a acontecer porem-me um sim em lugar de um não" (idem).

Entretanto, poderíamos especular, se o enredo de Saramago parece tão claramente interessado no conflito subjacente entre escritura original e leitura, ou entre Autor e revisor, e se considerarmos o texto de Freud acima citado, de acordo com o qual "o herói de todo o devaneio, como o de toda história” é "Sua Majestade o Ego" (1983: 26), como poderíamos explicar a criação de um personagem revisor, ao mesmo tempo explicitamente "subversivo" e tão bem-sucedido em suas investidas contra os direitos e os privilégios autorais? Ou seja, como poderíamos explicar o fato de que, num texto que, entre outros temas, aborda a rivalidade entre Autor e revisor, é o revisor subversivo e inadequadamente "visível" quem acaba levando a melhor? Estaria o Autor sugerindo que, em algum nível subterrâneo, abre mão da autoridade e dos direitos geralmente associados à autoria? Não, exatamente. Num trecho particularmente significativo, o narrador onisciente - o porta-voz do Autor, ou, talvez, do "Ego" do Autor - inesperadamente interrompe o princípio de verossimilhança da narrativa do primeiro telefonema amoroso entre o revisor e Maria Sara, deixando claro quem controla o destino (e os desatinos) do revisor e quem determina os rumos da história. Afinal, tanto o revisor como sua inesperada boa fortuna dependem exclusivamente dos "caprichos" do Autor e estão inteiramente sob o domínio de quem escreve o "verdadeiro" romance intitulado História do Cerco de Lisboa:

Estão felizes, ambos, e a um ponto tal que será grande injustiça separar-nos de um para ficar a falar do outro, como mais ou menos seremos obrigados a fazer, porquanto, conforme ficou demonstrado num outro mais fantasioso relato, é física e mental- 
mente impossível descrever os actos simultâneos de duas personagens, mormente se elas estão longe uma da outra, ao sabor dos caprichos e preferências de um narrador sempre mais preocupado com o que julga serem os interesses objectivos da sua narrativa do que com as esperanças em absoluto legítimas desta ou daquela personagem, ainda que secundária, de ver preferidos os seus mais modestos dizeres e miúdas acções aos importantes feitos e palavras dos protagonistas e dos heróis. (239-240; minha ênfase).

Terminada a leitura, sabemos, "concretamente", que História do Cerco de Lisboa é, na realidade, o título do romance consagrado de José Saramago e que tanto seu personagem, Raimundo Silva, quanto o texto História do Cerco de Lisboa que este se dedica a escrever (baseado, por sua vez, no livro homônimo que revisara), não passam de ficções criadas e manipuladas pelo Autor, como marionetes, a serviço de seus "interesses objectivos". Terminada a leitura, sabemos que, enquanto Saramago é o verdadeiro Autor do "original" História do Cerco de Lisboa, o revisor Raimundo - que, aliás, nunca deixa de ser chamado de revisor, mesmo quando começa a se tornar autor - permanecerá, para sempre, como o Pierre Menard de Borges, apenas tentando rescrever um texto preexistente, movido por seu desejo de ser autor e de permanecer no universo privilegiado daqueles que ousam transformar esse desejo em realidade. Assim, os "interesses objectivos" do narrador (e, portanto, do Autor) parecem se concentrar, sobretudo, numa idealização romântica do seu próprio poder autoral e do contexto em que esse poder é exercido e reconhecido, estabelecendo um contraste marcante entre essa situação extraordinária e a precariedade do contexto geralmente associado ao revisor e aos outros profissionais que realizam trabalho igualmente "secundário". O enredo de Saramago dramatiza e romanceia não apenas o poder do Autor, enquanto senhor absoluto de sua narrativa e de seus personagens, mas, também, essa assimetria tão clara entre originalidade e reprodução, entre criação e leitura, firmemente entranhada na matriz de uma cultura que aprendeu a valorizar o primeiro elemento dessa oposição e, ao mesmo tempo, a menosprezar e a marginalizar o segundo.

Ao contexto dessa leitura de História do Cerco de Lisboa, em que ao Autor e ao Original se atribuem poderes quase divinos, proponho trazer mais uma narrativa exemplar, o mito de Babel, que também parte de uma oposição hierárquica semelhante e, não por acaso, se encontra intimamente associado à tradução e à forma como esta tem sido tratada na cultura ocidental. Segundo a narrativa bíblica, as famílias dos filhos de Noé decidiram construir uma cidade e uma torre que pudesse atingir o céu e obter, 
dessa forma, os atributos e os privilégios exclusivos de Deus. O que os unia, além da ambiciosa meta, era a possibilidade de compreensão entre todos e a capacidade de união. De acordo com a versão de Louis Segond, publicada na França em 1910, assim conclamavam o povo os entusiastas da construção: "Venham! Vamos fazer tijolos e prepará-los na fogueira [...] Vamos! Vamos construir uma cidade e uma torre para nós mesmos e o pico da torre alcançará o céu, vamos criar um nome para nós mesmos para que não fiquemos espalhados por toda a terra!" (citado em Derrida 1985: 168).

Essa tentativa de construção de uma torre e de conquista de um nome próprio, expressão do desejo humano de se igualar a Deus e de obter seu poder autoral de nomear e criar, revela, em primeiro lugar, a radicalidade da oposição entre o divino e o humano. Enquanto que ao primeiro se associa o privilégio do poder absoluto, da imortalidade, da onipotência e da onisciência e, obviamente, também da verdade e do conhecimento absolutos que prescindem, inclusive, de qualquer linguagem, o segundo deve se contentar com o castigo eterno da posição subalterna, à mercê das leis e do controle do primeiro. A reação divina à ameaça da torre torna ainda mais exacerbada a diferença entre os dois lados da oposição entre Deus e os humanos já que estes, além da posição subalterna, tiveram que enfrentar, desde a ousadia de Babel, também a maldição da dispersão e da multiplicidade das línguas. Aos pretensiosos construtores, o irado Deus, tão "humanamente" interessado em proteger seus privilégios, impôs não apenas a destruição da torre e das ilusões nela depositadas mas, sobretudo, a condenação à arbitrariedade da linguagem e, conseqüentemente, à inevitabilidade (e à impossibilidade) da tradução.

É claro o paralelo que se pode estabelecer entre a radical assimetria de poder que separa os humanos de Deus, no mito de Babel, e a oposição hierarquicamente marcada entre o revisor e o Autor, no universo armado em $A$ História do Cerco de Lisboa. Como no mito, o desejo de superar as "limitações" do humano e de atingir o poder divino de estabelecer significados e moldar a realidade se encontra intrinsecamente associado à necessidade de proteger o espaço e os privilégios que se associam à Autoria de qualquer ameaça que possa surgir a partir do desejo autoral de outros. Embora a figura autoral máxima representada por Deus no enredo de Babel tenha destruído a torre e impedido a ascensão dos descendentes de Noé aos céus, não se extinguiu a força do desejo que motivou seu ambicioso projeto. Se, como aprendemos, o mito de Babel representa a diversidade 
lingüística enquanto marca e sina dos seres humanos, estaremos, portanto, para sempre condenados a repetir a construção de textos/torres que tentamos proteger do olhar desejoso de outros que, exatamente como nós, também necessitam estabelecer seus domínios na tentativa de organizar a confusão pós-babélica que nos caracteriza como seres essencialmente não-divinos. Conseqüentemente, parecemos destinados também a não aceitar precisamente aquilo que nos define e distingue: a arbitrariedade da linguagem e a precariedade da interpretação que herdamos de Babel, tão bem representadas, por exemplo, em qualquer ato de leitura ou tradução. Uma das faces desse "destino" é exatamente um certo desprezo por qualquer tipo de trabalho textual "secundário" que nos lembre o fracasso de tentar atingir o plano divino.

E-mail: rosearrojo@uol.com.br

Recebido em abril de 2002

\section{REFERÊNCIAS BibLIOGRÁFICAS}

Arrojo, Rosemary. 1986. Oficina de Tradução - A Teoria na Prática. São Paulo: Ática.

1993. Laplanche Traduz o Pai da Psicanálise: As Principais Cenas de um Romance Familiar. Tradução, Desconstrução e Psicanálise. Rio de Janeiro: Imago.

1993a . A Tradução e o Flagrante da Transferência: Algumas Aventuras Textuais como Dom Quixote e Pierre Menard. Tradução, Desconstrução e Psicanálise. Rio de Janeiro: Imago.

1995. Translation and Postmodernism in Calvino's Se una notte d'inverno un viaggiatore". La Traduzione-Saggi e Documenti II, LIBRI E RIVISTE D'ITALIA. Ministero per i Beni Culturali e Ambientali, Divisione Editoria: 41-56.

1998. 'O Tradutor Cleptomaníaco' e a Mudança de Paradigma nos Estudos da Tradução. Anais do I Congresso Ibero-Americano de Tradução e Interpretação (I CIATI) - Tradução, Interpretação e Cultura na Era da Globalização. São Paulo, Unibero: 99-102.

1998a The Revision of the Traditional Gap between Theory \& Practice \& the Empowerment of Translation in Postmodern Times. The Translator, Studies in Intercultural Communication, 4, $\mathrm{n}^{\circ}$ 1. St. Jerome Publishing: 25-48. 
2000. Borges e a Maldição de Babel: Escritura, Interpretação e Conflito. Jorge Schwartz (org.) Borges no Brasil. São Paulo, Editora UNESP:149-163.

2000a Algumas Relações entre Marginalidade e Prescritivismo: A Tradução e o Tradutor como Objetos de Pesquisa. Estudos Lingüísticos, 29. São Paulo: 43-51.

2000b A Modernidade e o Desprezo pela Tradução como Objeto de Pesquisa. Alfa, Revista de Lingǘstica, v. 44 (número especial). UNESP: 71-87.

2002. Writing, Interpeting, and the Power Struggle for the Control over Meaning - Exemplary Scenes from Kafka, Borges, and Kosztolányi. Gentzler, E. e M. Tymoszko (orgs.) Translation and Power. Amherst, University of Massachusetts Press: 63-79.

2002a (no prelo) The Power of Originals and the Scandal of Translation - A Reading of Edgar Allan Poe's 'The Oval Portrait'. Calzada Pérez, M. (org.), Apropos of Ideology. Translation Studies on Ideology/Ideologies in Translation Studies. Manchester, Sr. Jerome.

Borges, J. L. 1981. Pierre Menard, autor del Quijote. Ficciones. Madri: Aliança Editorial.

Chamberlain, L. 1992. Gender and the Metaphorics of Translation. Venuti, L. (org.) Retbinking Translation - Discourse, Subjectivity, Ideology. Nova York: Routledge.

Calvino, I. 1994. Se una notte d'inverno un viaggiatore. Milão: Oscar Mondadori.

Derrida, Jacques. 1985. Des Tours de Babel. Tradução de J. F. Graham. Graham, Joseph F. (org.) Difference in Translation. Ithaca e Londres: Cornell University Press: 165-207.

Freud, S. 1983. Creative Writers and Daydreaming. Kurzweil E. e W. Phillips (orgs.) Literature and Psychoanalysis. Nova York: Columbia University Press: 24-28.

Frota, M. P. 2000. A Singularidade na Escrita Tradutora - Linguagem e Subjetividade nos Estudos da Tradução, na Lingüística e na Psicanálise. Campinas: Pontes, Fapesp.

Kosztolányi, D. 1996. O Tradutor Cleptomaníaco. O Tradutor Cleptomaníaco e Outras Histórias de Kornél Esti. Tradução de Ladislao Szabo. São Paulo: Editora 34: 7-10.

Schrift, A. D. 1990. Nietzsche and the Question of Interpretation - Between Hermeneutics and Deconstruction. New York, London: Routledge. 
Saramago, J. 1998. História do Cerco de Lisboa. São Paulo: Companhia das Letras.

Saramago, J. 1997. History of the Siege of Lisbon. Tradução de Giovanni Pontiero. Nova York, Harcourt Brace \& Company.

White, E. 1997. The Subversive Proofreader. The New York Times Book Review, 13 de julho, The New York Times on The Web 